\title{
Social and Emotional Learning in the Kindergarten Classroom: Evaluation of the Strong Start Curriculum
}

\author{
Thomas J. Kramer \\ Paul Caldarella \\ Paul_Caldarella@byu.edu \\ Lynnette Christensen \\ lynnette_christensen@byu.edu \\ Ryan H. Shatzer
}

Follow this and additional works at: https://scholarsarchive.byu.edu/facpub

Part of the Teacher Education and Professional Development Commons

\section{Original Publication Citation}

Kramer, T., J., Caldarella, P., Christensen, L., \& Shatzer, R. H. (21). Social-emotional learning in kindergarten classrooms: Evaluation of the Strong Start curriculum. Early Childhood Education Journal, 37(4), 33-39

\section{BYU ScholarsArchive Citation}

Kramer, Thomas J.; Caldarella, Paul; Christensen, Lynnette; and Shatzer, Ryan H., "Social and Emotional Learning in the Kindergarten Classroom: Evaluation of the Strong Start Curriculum" (2010). Faculty Publications. 112.

https://scholarsarchive.byu.edu/facpub/112

This Peer-Reviewed Article is brought to you for free and open access by BYU ScholarsArchive. It has been accepted for inclusion in Faculty Publications by an authorized administrator of BYU ScholarsArchive. For more information, please contact ellen_amatangelo@byu.edu. 
Title: Social and Emotional Learning in the Kindergarten Classroom:

Evaluation of the Strong Start Curriculum

Authors: Thomas J. Kramer, Paul Caldarella, Lynnette Christensen, Ryan H. Shatzer

Address: Brigham Young University, David O. McKay School of Education, Provo, Utah 84602

Corresponding author: Paul Caldarella, Ph.D.

Address: Department of Counseling Psychology and Special Education

Center for the Improvement of Teacher Education and Schooling

MCKB 340

Provo, Utah, USA 84602

Email: paul_caldarella@byu.edu

Phone: 1-801-422-5081

Fax: 1-801-422-0198 


\begin{abstract}
There has been increasing interest in the promotion of social and emotional learning in schools, and research has shown positive outcomes. However, relatively few studies have been conducted in kindergarten classrooms or considered the feasibility of kindergarten implementation. This study examined the effects of Strong Start on the social and emotional competence of 67 kindergarten students, using a time-series design. Four kindergarten teachers taught the ten Strong Start lessons in their classrooms. Results indicated gains in students' prosocial behaviors and decreases in internalizing behaviors, as rated by teachers and parents. Implementation integrity and teachers' ratings of social validity were high, suggesting the program's feasibility and potential effectiveness in natural classroom settings. Limitations and implications are discussed.
\end{abstract}


Social and Emotional Learning in the Kindergarten Classroom:

Evaluation of the Strong Start Curriculum

Early childhood is a critical period in social and emotional development. By preschool most children are beginning to distinguish between positive and negative emotions, and are also learning how to regulate their own emotions (Izard, Trentacosta, King, \& Mostow, 2004). Affective development generally precedes cognitive and behavioral development, as children experience emotions and react to them long before they are able to verbalize or cope (Greenberg \& Snell, 1997). However, social and emotional competencies do not unfold automatically; rather they are strongly influenced by the child's early learning environment (Joseph \& Strain, 2003).

Children who repeatedly misread emotions may be rejected by peers if they act on those misperceptions (Seifer, Gouley, Miller, \& Zakriski, 2004). As interactions with age mates increase, so do the social and emotional skills required. Young children often use maladaptive coping strategies, such as distancing (withdrawal), internalizing, externalizing, and denial (Denham \& Weissberg, 2004). Though many internalizing problems, such as anxiety or depression, may be less apparent to teachers or caregivers than the more disruptive externalizing problems, they have been shown to impose a greater burden on mental health (Kimber, Sandell, \& Bremberg, 2008).

Evidence suggests that emotional and behavioral problems during preschool often persist. One study showed that children's understanding of emotions at age five significantly predicted academic competence at age nine, even after controlling for verbal ability and temperament (Izard et al., 2001). Emotional and behavioral difficulties in young students both negatively impact current academics and can lead to tragic long-term 
outcomes such as depression, school dropout, unemployment, and anti-social or violent activities (Denham \& Weissberg, 2004; Seifer et al., 2004). Additionally, evidence indicates that without intervention many of these social-emotional problems become less amenable to intervention after age eight (Walker, Ramsey, \& Gresham, 2004). Some have estimated that as many as $20 \%$ of students have emotional or behavioral problems and that $84 \%$ do not receive appropriate interventions (Walker, 2004). Many teachers feel they have inadequate training to address these children's needs (Cook, 2002).

In response to these problems, a large number of school-based programs have been developed with topics ranging from promotion of health to prevention of violence, substance abuse, and teen pregnancy. In particular, social and emotional learning (SEL) programs have been the focus of much attention. Although there is no uniform definition of SEL, it is broadly designated by the Collaborative for Academic, Social, and Emotional Learning (CASEL) as the process for acquiring the skills needed to recognize and manage emotions, develop caring and concern for others, make responsible decisions, build positive relationships, and handle challenging situations constructively (CASEL, 2009). Because school is already established as a natural forum for structured learning, it is considered an ideal environment for promoting social and emotional competence (Ross, Powell, \& Elias, 2002; Zins, Bloodworth, Weissberg, \& Walsberg, 2004).

Evidence from a large-scale meta-analysis conducted by CASEL indicated that SEL programs have positive effects on students' social-emotional skills, social behaviors, conduct problems, emotional distress, academic performance, and attitudes towards self, others, and school (Payton et al., 2008). SEL interventions have been effective across 
multiple settings: in school and after school, in urban and rural areas, and for racially and ethnically diverse students. Follow-up data also indicated that effects were maintained over time, though they were not as strong as immediately after the intervention. Payton et al. also noted that the programs were more effective when conducted by the school teachers rather than outside researchers.

Even though evidence supports the effectiveness of SEL, many schools are still reluctant to implement such programs (Ennett et al., 2003). This research-to-practice gap is all too common in education (Walker \& Gresham, 2003). It seems the primary concern raised by school personnel is that SEL programs would compete with other high priority activities (Seifer et al., 2004). Often if an immediate clear benefit to academic progress is not established, schools will hesitate to engage in non-essential programming (Zins et al., 2004). This view remains, despite research clearly linking social-emotional learning to academic achievement (Payton et al., 2008).

Another concern is scarcity of resources. If the cost of implementation or the number of people or materials required is too high, it is unlikely that an SEL program will be approved by school personnel or implemented effectively. Most research appears to have focused on what is achieved by researchers in rigorously controlled laboratory experiments (efficacy) while paying less attention to what is seen in actual practice in complex school settings (effectiveness) (Merrell \& Buchanan, 2006). Although a program may show efficacy, unless it can be implemented as designed in typical school settings with implementation integrity, it is unlikely to prove effective.

Implementation integrity has been adequately measured in relatively few programs, although poor implementation is a major contributor to a program's failure 
(Domitrovich \& Greenberg, 2000; Ialongo et al., 1999). Any conclusions that might be drawn regarding program outcomes are necessarily weakened when implementation integrity is not addressed (Domitrovich \& Greenberg). A well designed and implemented program will allow enough flexibility to adapt to changing circumstances, while aiming to achieve sustainability and integrity to core principles even after initial training and support are withdrawn (Han \& Weiss, 2005). Several factors influence implementation integrity, including school principals' support and teachers' beliefs about the program's acceptability and anticipated effectiveness. Additionally, programs that are implemented by existing school personnel, are time efficient, and employ a manual are more likely to achieve implementation integrity (Han \& Weiss).

Another aspect that must be considered when evaluating an SEL program is its reach. Educational researchers have begun to think of prevention in terms of the threetiered model, or triangle (Walker, 2004). At the base of the triangle are the $80 \%$ of students in need of universal support, which is considered primary prevention. The remaining students make up the targeted (15\%) and indicated (5\%) levels, which require more intensive support. The benefit of universal prevention is its reach. As all students receive the prevention, they benefit from the protective factors that will keep difficulties from increasing and ultimately reduce the number of students who end up at greater risk-at the upper tiers of the triangle. This method is able to reach the largest number of students with the smallest amount of resources (Merrell, Parisi, \& Whitcomb, 2007).

The current study evaluated the use of an SEL curriculum, Strong Start (Merrell et al., 2007), as a universal prevention program for kindergarten students. A previous study of this curriculum in a second grade classroom showed significant improvements in 
students' prosocial behaviors and a decrease in internalizing behaviors (Caldarella, Christensen, Kramer, \& Kronmiller, 2009). Other studies of the Strong Kids series, grades 3-12, have shown increases in emotion knowledge and reductions in negative emotion symptoms (Merrell, Juskelis, Tran, \& Buchanan, 2008). The current study appears to be the first to evaluate Strong Start in kindergarten classes, the lower agerange for which the curriculum was intended. Three specific research questions were addressed:

1) What effects does the curriculum have on teacher and parent ratings of the social and emotional competence of kindergarten students?

2) Are kindergarten teachers able to implement the curriculum with integrity?

3) Do teachers and parents view the curriculum as socially valid (e.g., acceptable, feasible, and valuable)?

\section{Method}

\section{Participants and Setting}

Participants in this study included 4 kindergarten teachers, 67 students, and 67 parents or caregivers. The setting was a suburban Utah elementary school with a student population of 759: 80\% Caucasian, 14\% Hispanic, and 6\% from other ethnic groups. Nearly $50 \%$ percent of the students received free or reduced priced lunch.

Kindergarten teachers at the participating school had previously agreed to implement the Strong Start social and emotional learning curriculum in their classrooms. The participating teachers had an average of 12 years of teaching experience. All held a bachelor's degree in elementary education; one also had a master's degree in teaching 
and learning, and one had an endorsement in English as a Second Language. Three were Caucasian, and one was Pacific Islander.

The class sizes ranged from 15 to 22 students. Of the 78 students enrolled in the participating classes, parental consent was not obtained for 8 students, and 3 were dropped from the study due to attrition, resulting in a sample of 67 students. Students were 5 or 6 years old; $55 \%$ were female; $85 \%$ were Caucasian, $9 \%$ Hispanic, and $6 \%$ from other ethnic groups.

\section{Design and Analysis}

For this study a time-series design was chosen (Gall, Gall, \& Borg, 2003) because it allows for experimental manipulation of independent variables without the need for a control group. Teachers and parents completed behavior rating scales for each student on four separate occasions: twice before the intervention (pre) with a six-week interval between them, and twice following the intervention (post) also with a six-week interval between them. Teacher response rate across the four rating intervals was $100 \%$, while the parent response rate across the four rating intervals was $96 \%$. In order to find the differences between pretests and posttests, repeated measure ANOVA and simple contrasts were used. Effect sizes were calculated using Cohen's $d$ by comparing the mean pretest score with the mean posttest score.

\section{Dependent Variable and Measures}

The dependent variable of this study was the social and emotional competence of the kindergarten students. The aspects of social and emotional competence that were specifically measured were internalizing behaviors and peer-related prosocial behaviors. Though self-report measures are available, these were not a feasible option for this study 
given the lengthy interview-style assessment which is required for young children. For this reason teacher and parent ratings of student behaviors were used.

Teachers completed the peer relations subscale of the School Social Behavior Scale $\left(2^{\text {nd }}\right.$ ed.) (SSBS; Merrell 2002), a standardized, norm-referenced measure used to assess student prosocial behaviors. This 14-item subscale measures social skills and attributes that are important in establishing positive relationships and gaining social acceptance from peers. The scale includes items such as "Offers help to other students when needed" and "Is good at initiating or joining conversations with peers." This scale has an internal consistency (alpha) rating of .96 for elementary teachers. Parents completed the 17-item peer relations subscale of the Home and Community Social Behavior Scales (HCSBS; Merrell \& Caldarella, 2002), a home version of the SSBS, similar in content and design. Parents and teachers also rated students using the internalizing subscale of the Social Skills Rating System (SSRS; Gresham \& Elliot, 1990). This measure is also norm-referenced and standardized; it has a reported internal consistency of .78. Sample items include "Appears lonely" and "Acts sad or depressed" (Gresham \& Elliott, p. 4). For each measure, evaluators rated the frequency of students' observed behavior on a 5-point Likert scale, ranging from 1 (never) to 5 (frequently).

\section{Independent Variable}

The independent variable was the implementation of Strong Start. Only typical classroom materials were needed for implementation, although a stuffed animal was used as recommended in the Strong Start manual to serve as a mascot and contribute to scenarios and role play. The curriculum focused on fostering prosocial behaviors and competencies and preventing internalizing disorders. This curriculum was made up of 10 
lessons covering topics such as recognizing one's own and others' feelings, handling anger and anxiety, being a friend, and solving problems. These topics were taught through direct instruction, example scenarios, and role-play activities. The program relied heavily on the use of popular children's literature to explore the lesson topics and guide discussions.

Teachers were given a one-hour introduction to the curriculum before teaching the Strong Start lessons. Some studies of SEL curricula have examined the potential benefits of extensive training, teacher consultation, and ongoing feedback and support. However, because one purpose of this study was to assess feasibility, we aimed to simulate a more realistic scenario, one in which teachers likely wouldn't have additional supports. The lessons were taught weekly by the regular classroom teacher over a period of 10 weeks. As suggested in the curriculum, a Strong Start bulletin was sent home with students at the conclusion of each lesson, explaining to parents and guardians what was taught and encouraging them to reinforce the skills at home.

\section{Social Validity}

Teachers also completed a 26 -item social validity questionnaire, and parents completed a 6-item questionnaire, both using a 5-point Likert scale, ranging from 1 (strongly disagree) to 5 (strongly agree). The teacher questionnaire assessed the acceptability of the program's goals, procedures, and outcomes. The following items are typical: “Students' social and emotional concerns are great enough to warrant use of a curriculum such as Strong Start," "The length of lessons was appropriate for kindergarten students," and "Strong Start was a good way to prevent social and emotional problems." Several open-ended questions allowed for additional comments. Teachers were also 
interviewed following completion of the surveys. The briefer parent questionnaire inquired about parents' support of SEL efforts in schools, their awareness of and participation in the program, changes in their child's behavior, and their desire to have or not have their child to participate in an SEL program again.

\section{Implementation Integrity}

To measure implementation integrity a researcher was present for 35 of the 40 lessons $(88 \%)$, recording the number of lesson components fully completed and the length of each lesson. The amount of student participation was also measured via number of student responses. Teachers followed the curriculum closely, completing $92 \%$ of lesson components fully, which constitutes a high degree of implementation integrity. Lessons averaged 37 minutes, ranging from 20 to 58 minutes. The components most often omitted were brief reviews of previous lessons. Students averaged 32 responses per lesson, which shows active participation.

\section{Results}

\section{Teacher and Parent Ratings}

Results of the repeated measures ANOVA indicated statistically significant differences between pretest and posttest mean scores on both the SSBS and SSRS teacher ratings (see Table 1). Simple contrasts indicated that both posttests were significantly higher than the pretests on the SSBS scores, and both posttests were significantly lower than the pretests on the SSRS scales. All contrasts were significant at the $p<.001$ level. It should be noted that improved social functioning is indicated by an increase in SSBS scores (prosocial behaviors), and a decrease in SSRS scores (internalizing behaviors), which is consistent with these results. 
Results also indicated statistically significant differences between pretest and posttest mean scores on the HCSBS parent ratings of prosocial behaviors. Simple contrasts indicated that both posttests were significantly higher than both pretests $(p<$ .01). Parent ratings on the SSRS decreased from the pretests to posttests, but the differences were not statistically significant (see Table 1).

$<$ Insert Table 1>

\section{Social Validity Measure}

Teachers responded favorably when answering items about goals and outcomes of the Strong Start program. The goals of the program received an average acceptability rating of 4.34, and the program outcomes received a score of 4.11 on the 5-point scale. Teachers rated the program's procedures as more neutral at 3.29. Similarly, parents had an overall favorable view of the curriculum. Regarding the acceptability of SEL being taught in the schools, parents gave a rating of 4.66. A score of 4.09 indicated that the majority of parents noticed a change in their child's behavior or social-emotional knowledge. When asked about whether they would want their child to participate in an SEL program again, parents responded with a rating of 4.46 .

The open-ended questions at the end of the teacher validity questionnaire, as well as the follow-up interview, revealed that teachers found the curriculum to be an acceptable and feasible program for improving students' social and emotional competence. Regarding the goals of SEL, teachers felt that SEL is definitely necessary since often the "kids are coming to us in pieces, and they can't focus." Though they felt that ideally these skills should be taught in homes, since many homes will not teach them, it is critical they be taught in schools. One teacher related how for several months one 
student would regularly bring up her father's death and another student would speak of his father's suicide. A third student frequently spoke of his mom being in jail. "These are the kinds of issues facing them," she stated. "Some of the kids are in fight or flight mode; if they are stuck there, they cannot focus."

Though teachers generally held a favorable view of the curriculum, they faced several challenges with the procedures of implementation. The primary concern was the length of the lessons. All teachers responded independently that the lessons were too long for the attention span of kindergartners, who seemed to become fidgety after only 20 minutes. Additionally, teachers felt that some of the tasks seemed too difficult for kindergartners (e.g., making synonym lists for various emotions), and the lessons would have been stronger with more visual aids, better pictures, and more activities. The curriculum made use of a mascot (in this case a puppet) to demonstrate examples and initiate role-plays. Students enjoyed the mascot, but teachers would have appreciated more explicit instruction in how to incorporate it more extensively.

Teachers were generally pleased with the program's outcomes, feeling that it had had noticeable effects on their students. One teacher felt that the primary strength of the curriculum was providing students a way to talk about their issues using a common language. Teachers also noticed that students seemed to be doing better with skills taught in the curriculum, such as inviting other people to play and joining in activities--skills they found necessary on the playground. Also students seemed better at making friends and not excluding people--one teacher commenting that she did not see the little cliques forming that had been typical in her class. Several parents commented to teachers that Strong Start seemed to have helped their child cut down on tantrums and fits. One student 
who had initially displayed many internalizing problems that seemed likely to worsen began to "come out of her shell." Her teacher attributed this to the effects of the program, which "kept the isolation from continuing." Three teachers indicated that they would like to teach the curriculum again, while one teacher was neutral on this point. One teacher in particular was very enthusiastic in asserting that she was committed to teaching some kind of SEL each year.

\section{Discussion}

Results suggest that Strong Start can be an effective program for increasing prosocial behaviors among kindergarten students. Both teacher and parent ratings of students indicated a statistically significant increase in prosocial behaviors following implementation of the ten Strong Start lessons, an increase maintained at a 6-week follow-up rating. Additionally, both teachers and parents indicated meaningful changes in students' prosocial behavior, with very large and moderate effect sizes respectively. Prosocial behaviors, which are essential in building and maintaining peer and adult relationships, depend on children's ability to recognize and manage their own and others' emotions, skills taught in Strong Start. Having a strong relationship to adults and peers is linked with resilience in children (Greenberg, Domitrovich, \& Bumbarger, 2001).

Improvement in internalizing behaviors was not, however, as consistent. Although teachers reported a significant decline of internalizing behaviors after the intervention, parents indicated only a slight decrease. This is not entirely surprising, as a child's familiar home setting likely would not provoke the same levels of discomfort and internalizing behaviors as the school setting might. Children may manifest their internalizing behaviors more frequently at school (given the increased demands), and 
assuming that the curriculum had a positive effect, this could account for the greater change observed by teachers. Also, because internalizing behaviors are not easily observable, both symptoms and improvements might be easily overlooked. Another explanation is that students, on average, were experiencing few internalizing symptoms at pretest times. For these students the curriculum may have served a preventive function, as symptoms did not get worse and did show a slight decrease.

Strong Start has an emphasis on prevention of internalizing behaviors, and previous research has shown little impact of the curriculum on students' externalizing behaviors (Caldarella et al, 2009). Although teachers may find the externalizing behaviors of students to be quite challenging, the negative effects that internalizing behaviors can have on a child's outcome are equally severe (Kimber, Sandell, \& Bremberg, 2008). Internalizing students receive less attention in the classroom, and similarly have received less attention in research (Christensen, Young, \& Marchant, 2007). For these reasons this study chose to focus on the potential improvements in students' internalizing rather than externalizing behaviors.

Educators who are evaluating SEL programs and deciding which to implement must examine not only efficacy, but also feasibility. The results of implementation integrity data and the social validity questionnaires suggest that Strong Start does have a high likelihood of being acceptable and feasible for teachers to use. This was apparent from responses to open-ended questions and follow-up interviews in which teachers expressed their views that students were in need of such (SEL) programming, that lessons were easily implemented with little training or support, and that changes were seen in students' social and emotional knowledge and behaviors. However, teachers did have 
some reservations about Strong Start, primarily that lessons were too long for kindergarten children and that some of the activities were too difficult and not sufficiently active for this age group.

This study did have several limitations, which suggest that the results be interpreted with some caution. Because the teachers presented the lessons themselves, their ratings of students' improvements may have been biased. Another limitation regards the measures: Only subscales were used, thus limiting potential to make definitive assessments. The SSRS (Gresham \& Elliot, 1990), though widely used in research, is somewhat dated. It might have been better to use more current measures of kindergarten student behavior (e.g., Behavior Assessment System for Children - Second Edition; Reynolds \& Kamphaus, 2004). An evaluation of the effects of this program could also be strengthened by using child self-reports, especially with regards to internalizing symptoms, and also by including ratings from an independent (blind) observer. This study involved four classrooms of limited diversity. A larger scale study with a more diverse representation of students would allow the results to generalize to a wider population. Future research may also consider splitting the lessons and teaching them twice a week, to address teachers' main complaint of lesson length not matching students' attention span. Additionally, this study did not include a control group and randomization of students. However, because students are already established in classrooms and all students are entitled to the potential benefits of a treatment, randomization and control groups are often impractical for research in school settings. Although evidence is increasing in support of SEL programming, challenges in acceptability and implementation remain. Strong Start was designed with ease of 
implementation and time-feasibility as priorities, and the results of the current study support this claim. In addition to increasing prosocial behaviors among kindergarten students, Strong Start demonstrated potential as a brief and focused curriculum, acceptable to teachers and feasible to implement. 


\section{References}

Caldarella, P., Christensen, L., Kramer, T. J., \& Kronmiller, K. (2009). Promoting social and emotional learning in second grade students: A study of the Strong Start curriculum. Early Childhood Education Journal, 37(1), 51-56.

Christensen, L., Young, K. R., \& Marchant, M. (2007). Behavioral intervention planning: Increasing appropriate behavior of a socially withdrawn student. Education \& Treatment of Children, 30(4), 81-103.

Collaborative for Academic, Social, and Emotional Learning (CASEL). (2008).

Background on social and emotional learning. Retrieved July 30, 2009 from http://www.casel.org/downloads/SEL\&CASELbackground.pdf

Cook, B. G. (2002). Inclusive attitudes, strengths, and weaknesses of pre-service general educators enrolled in a curriculum infusion teacher preparation program. Teacher Education and Special Education, 25, 262-277.

Denham, S.A., \& Weissberg, R. P. (2004). Social-emotional learning in early childhood: What we know and where to go from here. In E. Chesebrough, P. King, T.P. Gullotta, \& M. Bloom (Eds.), A blueprint for the promotion of prosocial behavior in early childhood (pp. 13-50). New York: Kluwer Academic/Plenum Publishers.

Domitrovich, C. E., \& Greenberg, M. T. (2000). The study of implementation: Current findings from effective programs that prevent mental disorders in school-aged children. Journal of Educational \& Psychological Consultation, 11(2), 193-221.

Ennett, S. T., Ringwalt, C. L., Thorne, J., Rohrbach, L. A., Vincus, A., Simons-Rudolph, A., et al. (2003). A comparison of current practice in school-based substance use prevention programs with meta-analysis findings. Prevention Science, 4(1), 1-14. 
Gall, M., Gall, J., \& Borg, W. (2003). Educational Research: An Introduction (7th ed.). Boston: Allyn and Bacon.

Greenberg, M. T., \& Snell, J. L. (1997). Brain development and emotional development: The role of teaching in organizing the frontal lobe. In P. Salovey, D. J. Sluyter, P. Salovey, \& D. J. Sluyter (Eds.), Emotional development and emotional intelligence: Educational implications (pp. 93-126). New York: Basic Books.

Greenberg, M. T., Domitrovich, C., \& Bumbarger, B. (2001). The prevention of mental disorders in school-aged children: Current state of the field. Prevention \& Treatment, 4(1), 1a.

Gresham, F. M., \& Elliott, S.N. (1990). Social Skills Rating System manual. Circle Pines, MN: American Guidance Service.

Han, S. S., \& Weiss, B. (2005). Sustainability of teacher implementation of school-based mental health programs. Journal of Abnormal Child Psychology, 33(6), 665-679.

Ialongo, N. S., Werthamer, L., Kellam, S. G., Brown, C. H., Wang, S., \& Lin, Y. (1999). Proximal impact of two first-grade preventive interventions on the early risk behaviors for later substance abuse, depression, and antisocial behavior. American Journal of Community Psychology, 27(5), 599-641.

Izard, C. E., Trentacosta, C. J., King, K. A., \& Mostow, A. J. (2004). An emotion-based prevention program for head start children. Early Education and Development, 15(4), 407-422.

Izard, C., Fine, S., Schultz, D., Mostow, A., Ackerman, B., \& Youngstrom, E. (2001). Emotion knowledge as a predictor of social behavior and academic competence in children at risk. Psychological Science, 12(1), 352-352. 
Joseph, G. E., \& Strain, P. S. (2003). Comprehensive evidence-based social-emotional curricula for young children: An analysis of efficacious adoption potential. Topics in Early Childhood Special Education, 23(2), 65-76.

Kimber, B., Sandell, R., \& Bremberg, S. (2008). Social and emotional training in Swedish schools for the promotion of mental health: An effectiveness study of five years of intervention. Health Education Research, 23(6), 931-940.

Merrell, K. W. (2002). School Social Behavior Scales, second edition. Baltimore: Paul H Brookes Publishing.

Merrell, K. W., \& Buchanan, R. (2006). Intervention selection in school-based practice: Using public health models to enhance systems capacity of schools. School Psychology Review, 35(2), 167-180.

Merrell, K. W., \& Caldarella, P. (2002). Home and Community Social Behavior Scales. Baltimore: Paul H Brookes Publishing.

Merrell, K. W., Juskelis, M. P., Tran, O. K., \& Buchanan, R. (2008). Social and emotional learning in the classroom: Evaluation of Strong Kids and Strong Teens on students' social-emotional knowledge and symptoms. Journal of Applied School Psychology, 24(2), 209-224.

Merrell, K. W., Parisi, D. M., \& Whitcomb, S. A. (2007). Strong Start grades K-2: A social and emotional learning curriculum. Baltimore: Paul H Brookes Publishing.

Payton, J., Weissberg, R.P., Durlak, J.A., Dymnicki, A.B., Taylor, R.D., Schellinger, K.B., \& Pachan, M. (2008). The positive impact of social and emotional learning for kindergarten to eighth-grade students: Findings from three scientific reviews. Chicago: Collaborative for Academic, Social, and Emotional Learning. 
Reynolds, C.R., \& Kamphaus, R.W. (2004). Behavior assessment system for children (2nd ed.). Circle Pines, MN: American Guidance Service.

Ross, M. R., Powell, S. R., \& Elias, M. (2002). New roles for school psychologists: Addressing the social and emotional learning needs of students. School Psychology Review, 31(1), 43-52.

Seifer, R., Gouley, K., Miller, A. L., \& Zakriski, A. (2004). Implementation of the PATHS curriculum in an urban elementary school. Early Education and Development, 15(4), 471-485.

Walker, H. M. (2004). Commentary: Use of evidence-based intervention in schools: Where we've been, where we are, and where we need to go. School Psychology Review, 33(3), 398-407.

Walker, H. M., \& Gresham, F. M. (2003). School-related behavior disorders. In W. M. Reynolds \& G. E. Miller (Eds.), Handbook of psychology: Educational psychology, (Vol. 7, pp. 511-530). Hoboken, NJ: John Wiley \& Sons Inc.

Walker, H. M., Ramsey, E., \& Gresham, F. M. (2004). Antisocial behavior in school: Evidence-based practices (2nd ed.). Belmont, CA: Wadsworth Publishing.

Zins, J. E., Bloodworth, M. R., Weissberg, R. P., \& Walberg, H. J. (2004). The scientific base linking social and emotional learning to school success. In J. E. Zins et al. (Eds.), Building academic success on social and emotional learning: What does the research say? (pp. 3-22). New York: Teachers College Press. 
Table 1

Means and ANOVA Results for Teacher and Parent Ratings

\begin{tabular}{|c|c|c|c|c|c|c|c|c|}
\hline & Pre $_{1}$ & $\mathrm{Pre}_{2}$ & \multicolumn{2}{|c|}{ Post $_{1}$} & \multicolumn{2}{|c|}{ Post $_{2}$} & \multirow[b]{2}{*}{$F$} & \multirow[b]{2}{*}{$d$} \\
\hline & $M \quad(S D)$ & $M \quad(S D)$ & $M$ & $(S D)$ & $M$ & $(S D)$ & & \\
\hline \multicolumn{9}{|l|}{ Teacher $^{\mathrm{a}}$} \\
\hline SSBS & $44.52(11.71)$ & $47.36(10.12)$ & 58.46 & $(9.40)$ & 60.33 & $(9.91)$ & $138.06^{*}$ & 1.39 \\
\hline SSRS & $12.13 \quad(5.87)$ & 11.61 & 9.72 & $(4.59)$ & 9.40 & (3.99) & $13.86^{*}$ & .48 \\
\hline \multicolumn{9}{|l|}{ Parent ${ }^{b}$} \\
\hline HCSBS & 67.05 (11.74) & $68.32(11.18)$ & 71.33 & $(11.23)$ & 71.82 & $(9.92)$ & $9.52^{*}$ & .44 \\
\hline SSRS & $11.14 \quad(3.82)$ & 11.04 & 10.35 & $(3.52)$ & 10.88 & (3.93) & 1.47 & .18 \\
\hline
\end{tabular}

